\title{
A technical study of the materials and manufacturing process used in the Gallery wall paintings from the Jokhang temple, Tibet
}

\author{
Yan Song ${ }^{1 *} \mathbb{0}$, Feng Gao ${ }^{1}$, Austin Nevin², Juwen Guo ${ }^{1}$, Xiao Zhou' ${ }^{1}$, Shuya Wei ${ }^{3}$ and Qianqian $\mathrm{Li}^{3}$
}

\begin{abstract}
Wall paintings from the Jokhang temple, Lhasa, Tibet, China cover over $4000 \mathrm{~m}^{2}$. In order to protect these valuable paintings and to provide more conclusive information regarding the date of the painting scheme from the outer north Gallery, painting materials and techniques have been studied using optical and scanning electron microscopy, $X$-ray diffraction and raman spectroscopy. Organic materials were analysed with pyrolysis-gas chromatographymass spectrometry. The wall painting technique is typical of Tibetan paintings and includes multiple layers of locally sourced materials. Analytical results demonstrate the presence of natural and synthetic pigments, including cinnabar $(\mathrm{HgS})$, malachite $\left(\mathrm{CuCO}_{3} \cdot \mathrm{Cu}(\mathrm{OH})_{2}\right)$, azurite $\left(2 \mathrm{CuCO}_{3} \cdot \mathrm{Cu}(\mathrm{OH})_{2}\right)$, orpiment $\left(\mathrm{As}_{2} \mathrm{~S}_{3}\right)$, red lead $\left(\mathrm{Pb}_{3} \mathrm{O}_{4}\right)$, synthetic ultramarine blue $\left(\mathrm{Na}_{3} \mathrm{CaAl}_{3} \mathrm{Si}_{3} \mathrm{O}_{12} \mathrm{~S}\right)$ and emerald green $\left(\mathrm{Cu}\left(\mathrm{C}_{2} \mathrm{H}_{3} \mathrm{O}_{2}\right)_{2} \cdot 3 \mathrm{Cu}\left(\mathrm{AsO}_{2}\right)_{2}\right)$ which allow us to date the paintings from the mid to late nineteenth century. The binding media is a kind of animal glue which is likely to be bovine or yak glue, the traditional medium used in Tibet. Gilding was applied as gold powder or gold foil. In the past a sealing material or varnish containing drying oil (maybe tung oil) and pine resin was applied to the surface to protect the paintings.
\end{abstract}

Keywords: Tibet, Jokhang temple, Wall painting, Pigment, Binding media

\section{Introduction}

The Jokhang temple, also known as "Zula Kang" is located in the old city center of Lhasa. It has been the most important Tibetan Buddhist monastery since it was built in 647 C.E. (Tang Dynasty) by Songzain Gambo (the first king of Tubo Dynasty). Today, with an area of 25.1 thousand square meters, it is dedicated to Buddha, Bodhisattva, deities, patriarchs, and Dharma gods of Bonpo, Nyingma, Sakya, Kagyu and Gelug sects of Tibetan Buddhism [1, 2]. In 1961 the Jokhang temple was listed as a State-level key heritage site of China and included in the UNESCO World Heritage List in 2000.

Since the establishment of Jokhang temple, wall paintings have been an important part of the buildings [3]. Developed over more than thirteen centuries (from the Tubo dynasty to modern times), the wall painting areas

\footnotetext{
*Correspondence: sswallow@sohu.com

${ }^{1}$ Chinese Academy of Cultural Heritage, No. 2 Gaoyuan Street, North Fourth Ring Road, Chaoyang District, Beijing, China

Full list of author information is available at the end of the article
}

have gradually increased to more than $4000 \mathrm{~m}^{2}[4,5]$. The themes depicted in the paintings involve various aspects of Tibet's political, economic, historical, literary, religious and social life [6-12]. They are physical evidence of the evolution of painting technology, and the long history of Tibetan wall paintings. At present, most wall paintings preserved in Jokhang temple belong to the "Men Tang" style which was created by Menla Dondub (a Tibetan master who lived between the 15 and sixteenth century) $[13,14]$. Paintings are generally sophisticated and beautiful with rich colours (especially red, yellow, orange, green, blue and gold are most frequently used) [15-19]. They provide convincing solid evidence for study of Tibetan wall paintings. However, deterioration is apparent in the wall paintings due to the aging of historic buildings, long and strong exposure to light, severe fluctuations in temperature and humidity, and other natural or human factors. Major deterioration is manifested in deformation of walls, cracking, collapse, detachment of paint and plaster, faking of paint, smoke accumulation due to pollution from butter burning, and abrasions, all of which pose a 
threat to the long-term preservation of the paintings. In order to protect these valuable wall paintings, the Chinese Academy of Cultural Heritage $(\mathrm{CACH})$ carried out the conservation of various schemes from 2012 and work at the temple is ongoing. Before restoration, the materials and techniques of the wall paintings were studied and are the focus of this work. Figure 1 shows a scene from the Jokhang temple murals.

There are relatively few published studies on wall paintings from Tibet, and most research has focused on the history, iconography, techniques of painting, and religious and aesthetic value of depictions. Limited research has focused on the constituent of materials and techniques of Tibetan wall paintings. For example, Xiang studied the contents, characters and the iconography of the wall paintings from the Gallery of Jokhang temple [20]; others have studied the compositions of pigment, plaster layer and base layer of wall paintings samples from Jokhang temple [21-23]. The pigments present in the wall paintings from the Potala Palace, Norbulingka and Sakya Monastery have also been reported [24]. Data from these studies suggest that Tibetan murals have unique national characteristics in terms of their buildup or stratigraphy and the methods employed for their execution.

However, there is little literature about the varnishes and surface finishes which were routinely applied to the paintings and the binding media employed in Tibetan wall paintings. This work aims to study the techniques, pigments, binding media and varnish materials from fragments collected as part of conservation work carried out by $\mathrm{CACH}$ on the outside Gallery.

According to the records in "History of the Jokhang Temple": in 1783, the Dalai Lama VIII (1758-1804) invited painters to draw the wall paintings on the outside Gallery and courtyard [12]. Thus, wall paintings on the outside gallery were likely firstly executed in the late eighteenth or early nineteenth century. However the paintings have been extensively repaired and repainted, so the exact date of the scheme is unknown. A multianalytical approach was chosen for the analysis of samples based on published methods used for the study of wall paintings [25-33]. Cross-sections were prepared and studied using optical microscopy, Raman spectroscopy, and scanning electron microscopy-energy dispersive $\mathrm{x}$-ray spectroscopy. Fragments were also analysed by $\mathrm{X}$-ray diffraction for a complete characterisation of the ground materials. Binding media and varnish analysis was carried out with pyrolysis gas chromatography-mass spectrometry.

\section{Methods}

\section{Instrumentation}

1. Optical microscopy was carried out using a Leica DM4000 M (Germany) and samples were observed under various magnifications. The stereo microscopy

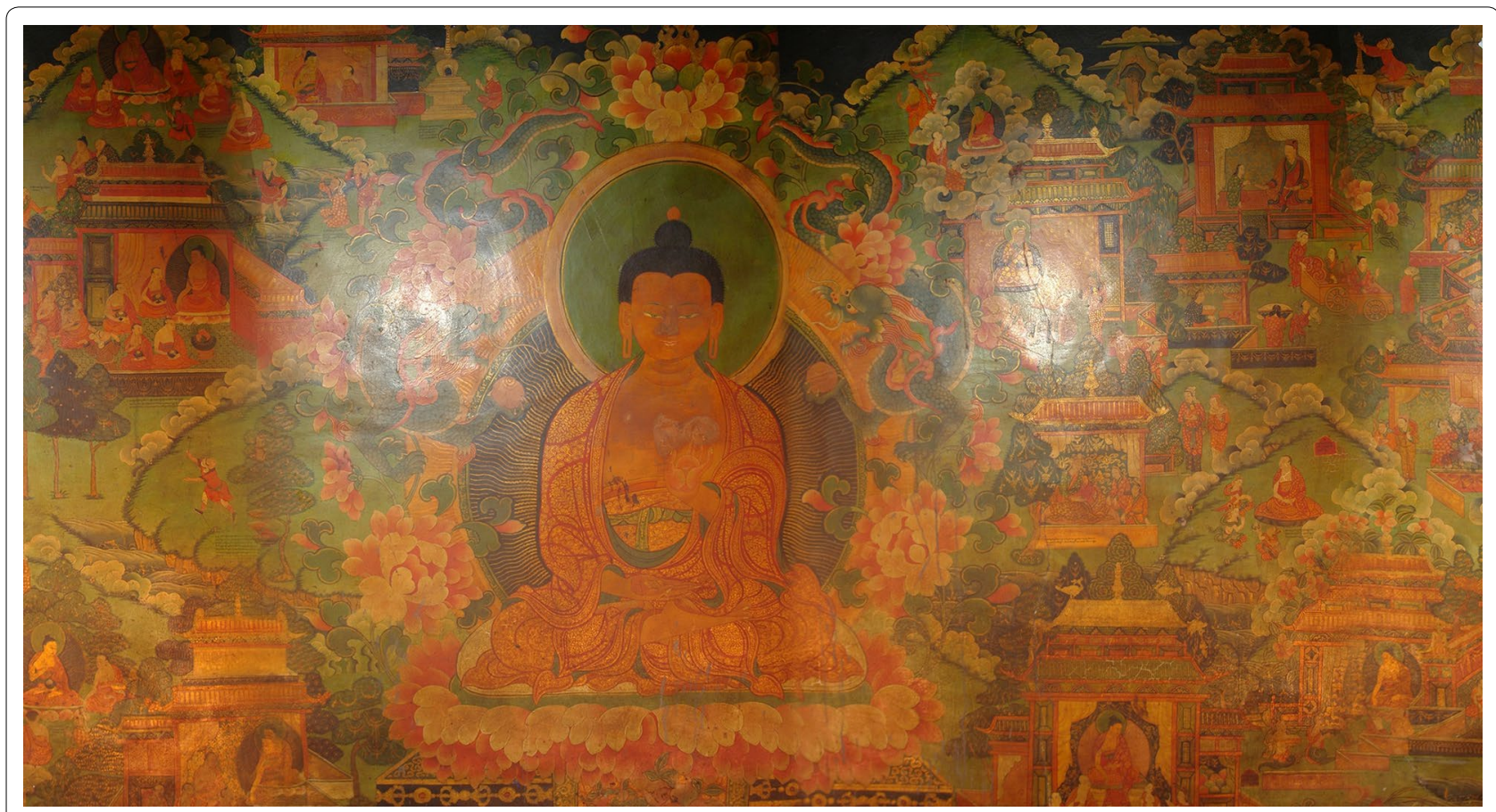

Fig. 1 Part of wall paintings on north outside Gallery wall of Jokhang temple 
was carried out using a Keyence VHX-900 (Japan) and samples were observed under various magnifications.

2. Scanning electron microscopy (SEM) was carried out using ZEISS EVO18, equipped with a SmartSEM system for data collection. Sample cross-sections were coated with gold prior to analysis. The range of magnification is $5-10^{6} \times$. Focused working distance is $2-145 \mathrm{~mm}$. The excitation voltage is $20 \mathrm{kV}$, and scanning time is $60 \mathrm{~s}$. Energy spectrum analysis was carried using Bruker Nano XFlash Detector 5010 Energy Spectrometer (EDS).

3. Raman spectroscopy was carried out on cross-sections with a HORIBA (JY Company, France) instrument equipped with Olympus BX-41 microscope at $50 \times$. The grating is $1200 \mathrm{~T}$ (line $/ \mathrm{mm}$ ). The spectrometer is calibrated by monocrystalline silicon. The laser wavelengths employed were 532 and $785 \mathrm{~nm}$, with an acquisition time of 20-30 s, and 4-6 acquisitions per spectrum. Red, yellow and black pigments were analysed with the $785 \mathrm{~nm}$ laser. While blue, green and white pigments were tested with $532 \mathrm{~nm}$. The power on samples was kept as low as possible with suitable data achievable with powers of 2-3 mW.

4. Small samples of the fragments and powder collected on site and local soil samples were subjected to X-ray diffraction (XRD). A TTRIII (Rigaku, Japan) $\mathrm{X}$-ray diffractometer was used for analysis. The X-ray emitter maximum output power is $18 \mathrm{kw}$, tube voltage is $20-60 \mathrm{kV}$, tube current is $10-30 \mathrm{~mA}$, target is $\mathrm{Cu}$, and focus size is $0.5 \mathrm{~mm} \times 10 \mathrm{~mm}$. Measurement range is $10^{\circ} \leq 2 \theta \leq 80^{\circ}$, with a scanning speed of $10^{\circ} /$ min.

5. Microsamples were analysed by pyrolysis-gas chromatography-mass spectrometry (Py-GC/MS). For the analysis $0.2 \mathrm{mg}$ sample was ground into powder and placed into a thermal cracking sample cup. $3 \mu \mathrm{L}$ TMAH solution (four methyl ammonium hydroxide, 25\%) was added in the cup and put it for an hour to make them fully dissolved. Samples were then dried prior to analysis using a Thermal cracking apparatus (PY-3030D, Frontier Lab, Japan), GC/MS (QP2010Ultra, Shimadzu, Japan), Chromatographic column UA+-5 (Frontier Lab, stationary phase is $5 \%$ 2-methyl-2-phenyl-polysiloxane). The parameters for analysis were set as follows: the pyrolysis was performed at $600{ }^{\circ} \mathrm{C}$ for $10 \mathrm{~s}$; the pyrolysis interface: $300{ }^{\circ} \mathrm{C}$; injector: $250{ }^{\circ} \mathrm{C}$; the oven temperature was set $40{ }^{\circ} \mathrm{C}$ for $5 \mathrm{~min}$, then up to $280^{\circ} \mathrm{C}$ at rate $10^{\circ} \mathrm{C} / \mathrm{min}$, hold for $20 \mathrm{~min}$.

\section{Sampling information}

All samples were taken from damaged parts or fragments that had fallen off. The samples, including three larger fragments and some smaller fragments and powder samples, were all taken from the outside Gallery of Jokhang temple.

\section{Sample preparation}

Some paint samples were observed directly under the optical microscope and examined by Raman spectroscopy. Local soil samples were ground into powder and analysed by XRD. The ground layer (including coarse clay layer and fine clay layer) were scraped from the samples and ground into powder which was analysed by XRD. Other samples were prepared as cross-sections using an epoxy resin and polished before examination.

\section{Results and discussion}

\section{Stratigraphy of the wall paintings}

Through the results of field investigations and sample analysis, the Jokhang temple wall painting is basically composed of five parts (from inside to outside): the basic support (flagstone wall), the ground layer, a white preparation layer, paint layer and a surface protective layer or varnish. The schematic diagram is shown in Fig. 2. It is noted that today traditional Tibetan wall paintings are made as follows: firstly, a clay mud (known locally as Ba-ga soil) is applied on a flagstone wall to smooth the wall and left to dry completely; a fine mud layer with loess is then applied; this is followed by a white preparation layer with Yang-ga soil; finally, after the white base dries, painters will brush a layer of wet glue on the white layer first, and then paint over the base. A varnish is usually applied to the final painting.

\section{The flagstone wall.}

The wall in the Jokhang temple is made of flagstones and is the basic support of the wall painting. Because the buildings are old, some walls have deformed and have shrunk under the influence of external environment. Thus, structural problems in the walls are one of the main factors leading to the loss of wall paintings.

2. The ground layer.

The ground is divided into three layers. The bottom is the Ba-ga soil, with coarse particles and mostly sandy loam, with a sand content not more than $12 \%$. The middle layer is made of thin loess, in which some flexible materials (such as straw and gaunt) are generally added to reinforce and increase the flexibility of the layer. The last layer is Ang-ba soil, which has a fine particle size. However, only the highest grade 


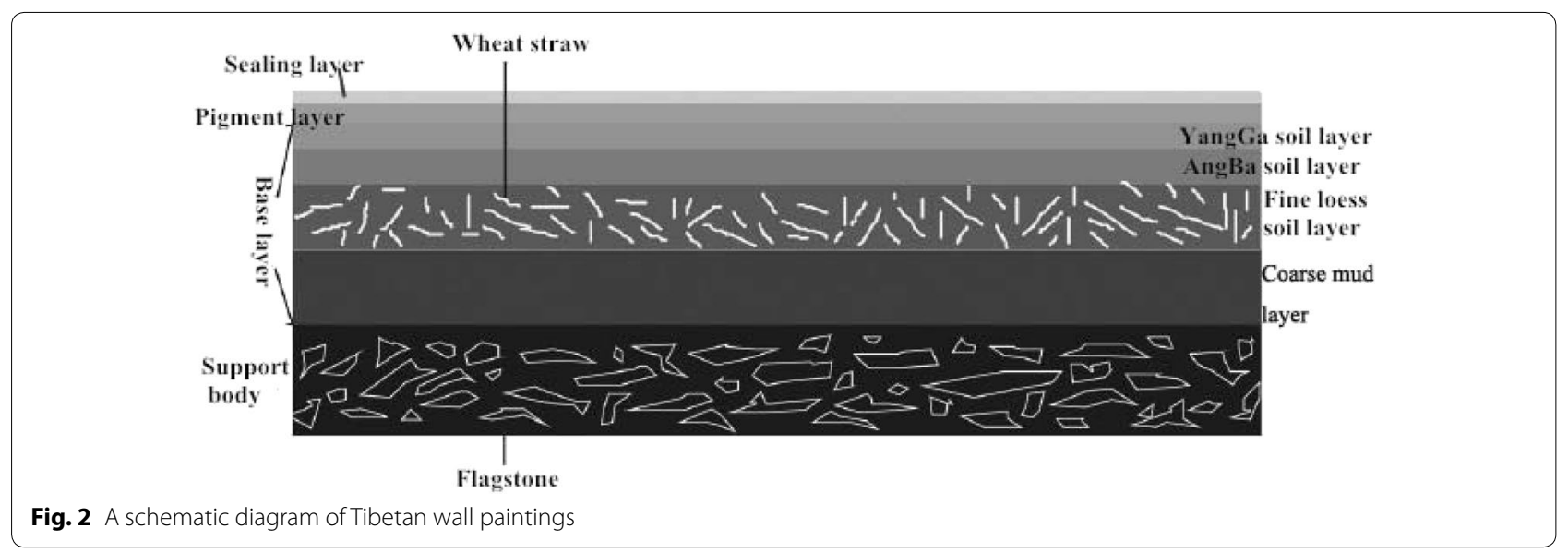

wall paintings have so many ground layers, and may do not contain the Ang-ba layer. Since the stones on the flagstone wall are uneven, the ground layer varies in thickness from about 5 to $1 \mathrm{~cm}$.

3. The preparation layer.

According to the local monks, the preparation layer is made of a local Yang-ga soil and is a very thin gray/ white layer. Analytical results identify the main component of the white powder layer of the samples as magnesite (magnesium carbonate).

4. The paint layers.

The color of the Jokhang temple mural is very rich. Blue, red, yellow, green and gold are mostly used and constitute the main thematic colors. The paintings are executed with meticulous painting with exact delineation (see Fig. 3a). In addition to the main painting scheme, there are two specific styles in the wall paintings: paint on a black background with gold lines (Fig. 3b), and paint on the gold-silver powder background in black (Fig. 3c). Traditionally, when painting, mineral pigments are ground into powder and a glue solution is added to make a liquid paint. After the color has been adjusted, the painter will use the paint to draw. The process of Tibetan wall painting is very strict and is described in detail elsewhere $[10,34,35]$.

\section{Technical study of three fragments}

Three larger fragments (Fig. 4) were sampled from the outside Gallery wall. Their surfaces are beautiful and lustrous coated with pigments, gold and a layer of protective material. Three layers (ground layer, white layer and

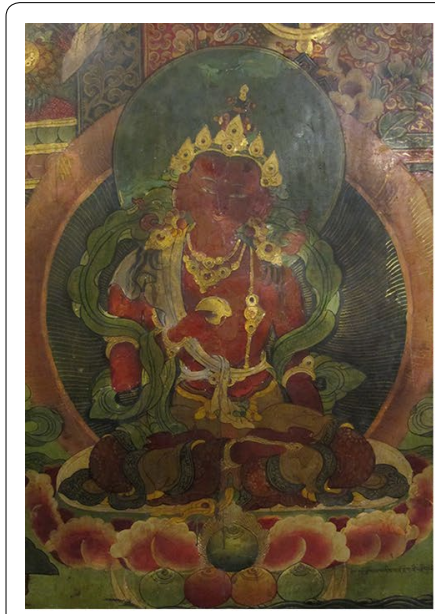

a

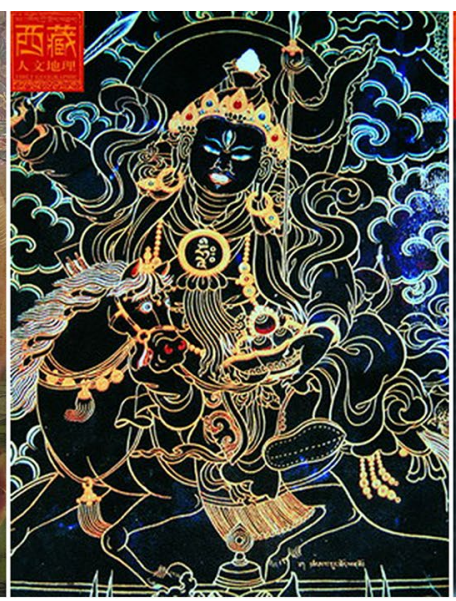

b

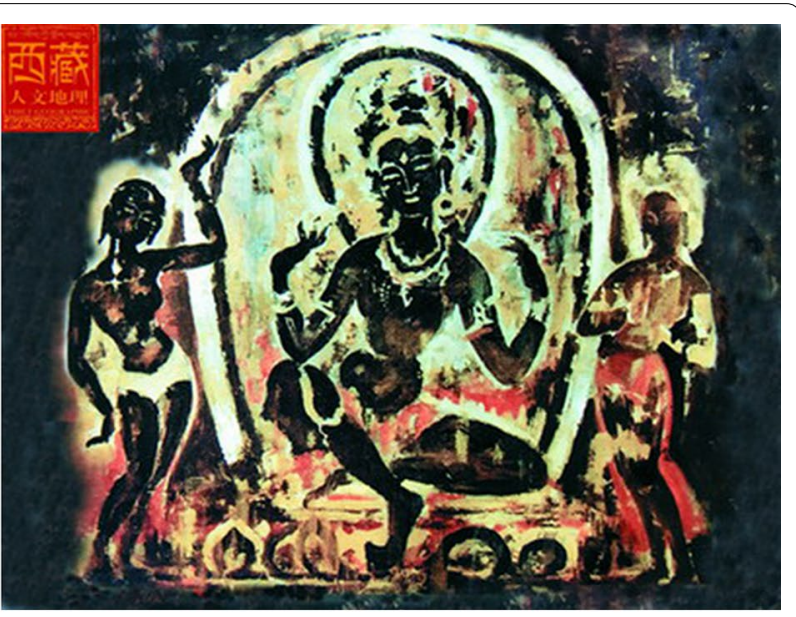

C

Fig. 3 Paint styles of the wall paintings ( $\mathbf{b}$ and $\mathbf{c}$ are from the Journal of Tibet Geographic Society); a main scheme, $\mathbf{b}$ the gold over black background, $\mathbf{c}$ the black over silver background 


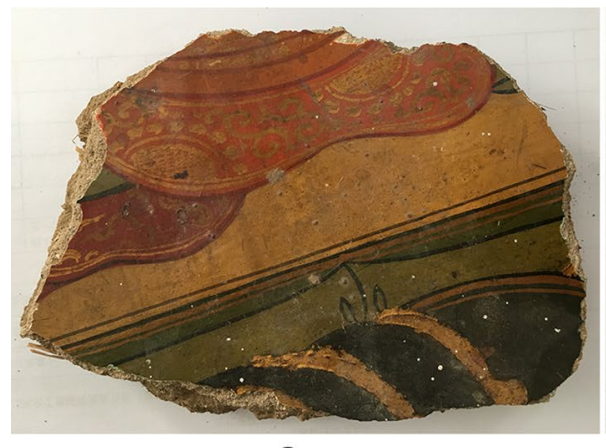

a

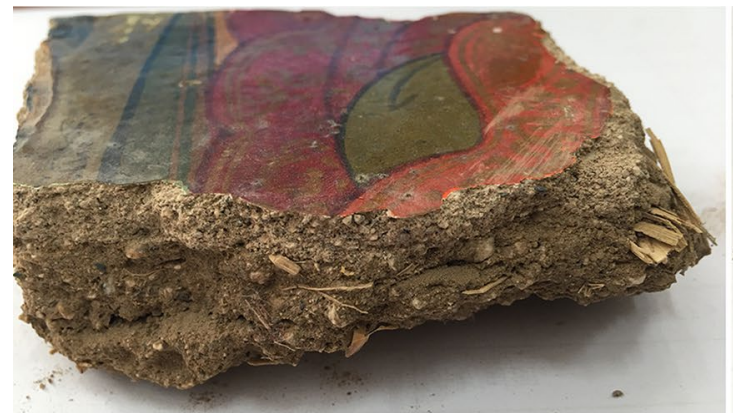

C

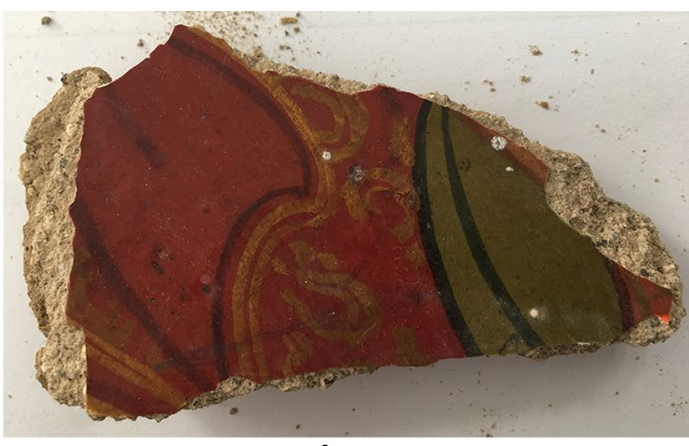

b

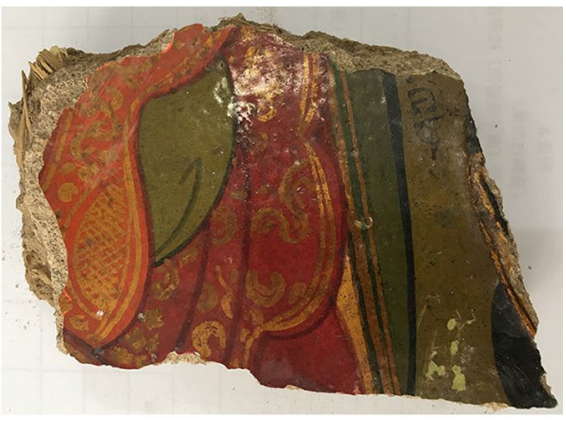

d

Fig. 4 Fragments collected from the outside gallery wall of Jokhang temple. a DZS-1, b DZS-2, c, d DZS-3

painting layer) can be seen clearly. The ground layers are thick and some flexible materials like wheat straw are mixed in the earthen plaster.

Examination under the stereo microscope (Fig. 5) shows that the surfaces of the fragments show signs of the accumulation of dust, discoloration, cracks, scaling, cracking, and pigment loss. The original color of the apparent black lines is actually blue when observed under the microscope, which is the result of long-term smoke accumulation. Gold powder can be observed over the pigment layer. A protective layer is evident on the surface and many micro bubbles and fine scratches are seen in this layer likely due to the brushing process, or the cracking and flaking of the varnish due to natural aging.

The thickness of the pigment layer is about $30-80 \mu \mathrm{m}$, and the white layer is about $50-120 \mu \mathrm{m}$ (Fig. 6). Gold powder can be seen over the paint layer and its thickness is about $20 \mu \mathrm{m}$ (Fig. 6d). It is noted that in some samples there is evidence of overpainting (Fig. 6b) where a thick (about $50 \mu \mathrm{m}$ ) white layer has been applied over the red layer, and is also covered in what could be varnish. This suggests the application of another ground or preparation layer for new paint.

The ground layer is thick and is usually divided into two parts: next to the white layer is a thin layer of loess with fine clay particles tightly connected and distribute uniformly; below the fine layer is a coarse mud layer with larger clay particles mixed with different sizes of sand and small stones. The main components of the coarse ground layer were identified by XRD to be quartz, albite and microcline, and the main components of the fine layer are quartz, albite, microcline and calcite. The major components of the coarse and fine layers are almost the same, thus it is likely that the same kind of clay was used. The local Ba-ga soil, Ang-ba soil and loess soil were sampled and tested by XRD which revealed the main components of these soils are all quartz, calcite and albite, and are basically the same as those of coarse layer, fine layer and Ang-ba layers of the wall painting samples.

In some samples the blue pigment is found mixed with the green pigment (Fig. 6e), and the orange pigment contains red and yellow particles (Fig. 6f). As noted by Dambar [36], traditional Tibetan wall paintings mainly use white, yellow, red, blue and green pigments either on their own or mixed to create different tones as observed in the samples studied as part of this work.

Under UV illumination, the thick varnish layer is apparent in cross-sections as a strongly luminescent material (Fig. 7). In some cross-sections two varnish layers are observed, and it is possible that they are of different composition. In addition, it is noted that the varnish penetrates into the sometimes abraded surface of the paint, 


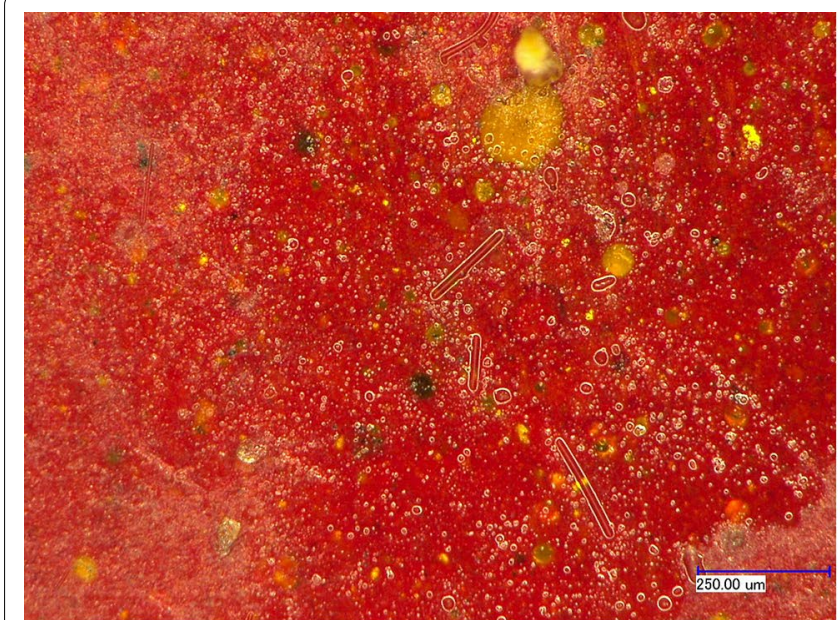

a

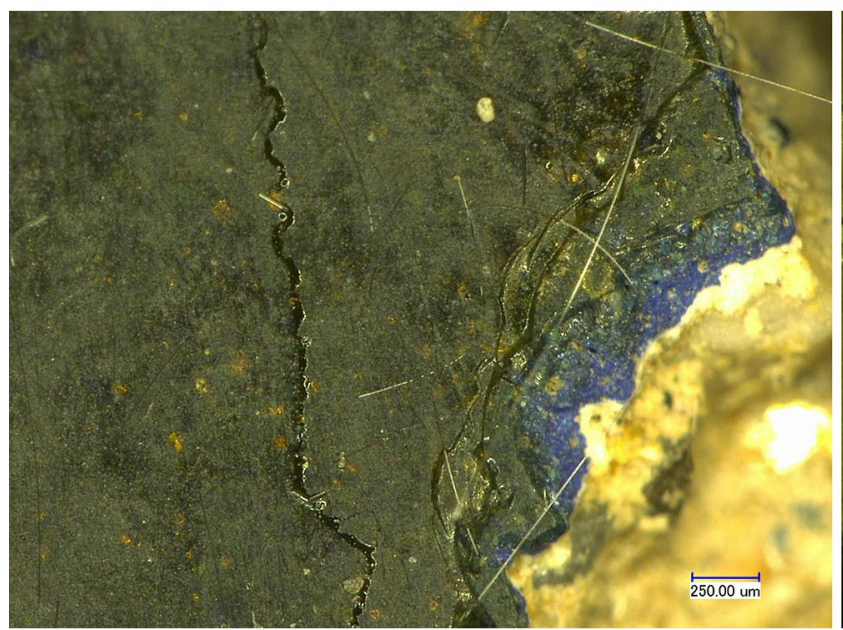

C

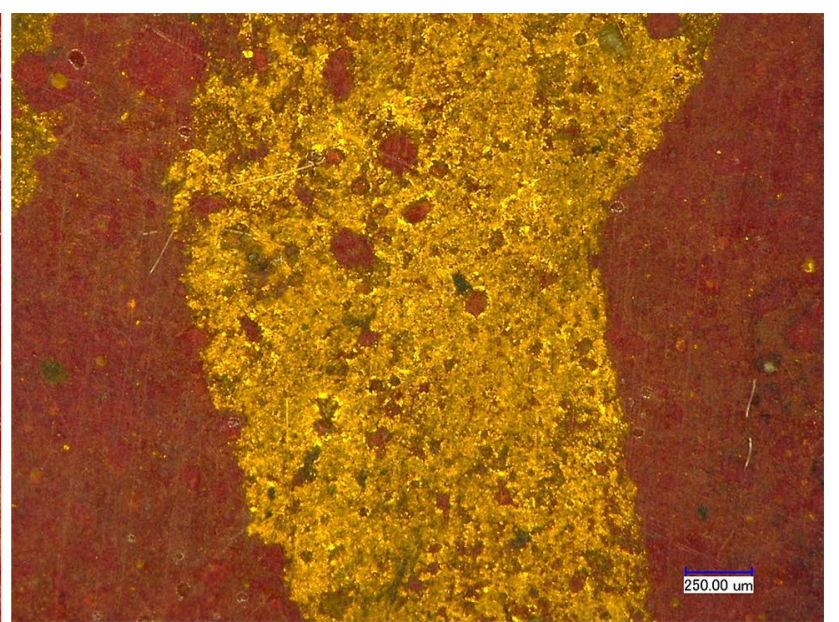

b

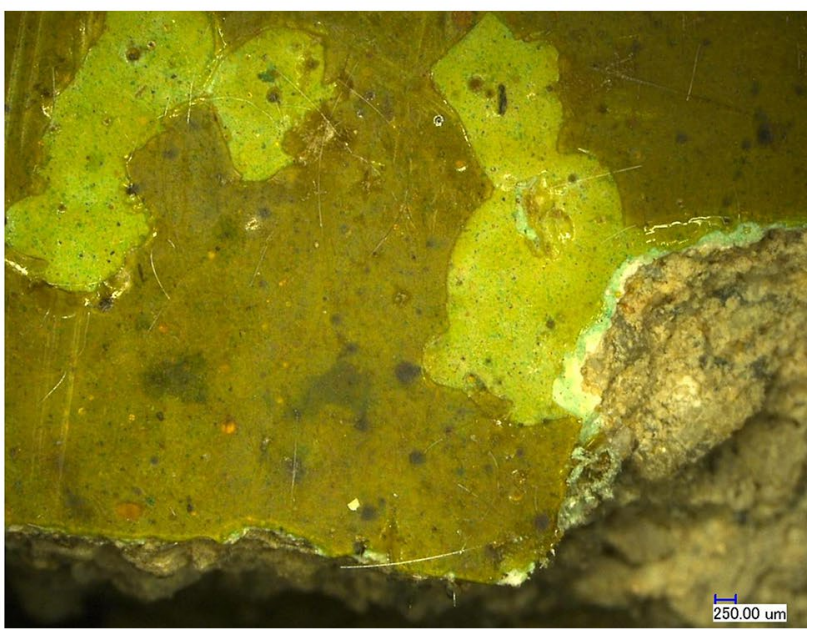

d

Fig. 5 The surface morphology of samples under 3D-microscope

and this is an indication that varnish was likely applied at a date later than the completion of the paintings.

The chemical composition of the pigments was determined by Raman spectroscopy and EDX. The test location for each analysis is showed in Additional file 1. Pigments were identified on the basis of a comparison between Raman bands and published databases of mineral and synthetic pigments $[37,38]$. The results are shown in Figs. 8 and 9 and indicate that the orange pigment is a mixture of red lead $\left(\mathrm{Pb}_{3} \mathrm{O}_{4}\right)$ and goethite $(\mathrm{FeO}(\mathrm{OH}))$, sometimes containing orpiment $\left(\mathrm{As}_{2} \mathrm{~S}_{3}\right)$; the yellow pigment is orpiment $\left(\mathrm{As}_{2} \mathrm{~S}_{3}\right)$; the red pigment is cinnabar $(\mathrm{HgS})$; the green pigments are either malachite $\left(\mathrm{CuCO}_{3} \cdot \mathrm{Cu}(\mathrm{OH})_{2}\right)$ or Emerald green [Paris green, $\left.\mathrm{Cu}\left(\mathrm{C}_{2} \mathrm{H}_{3} \mathrm{O}_{2}\right) \cdot 3 \mathrm{Cu}\left(\mathrm{AsO}_{2}\right)_{2}\right)$ ]; the blues are azurite $\left(2 \mathrm{CuCO}_{3} \cdot \mathrm{Cu}(\mathrm{OH})_{2}\right)$ or ultramarine blue
$\left(\mathrm{Na}_{3} \mathrm{CaAl}_{3} \mathrm{Si}_{3} \mathrm{O}_{12} \mathrm{~S}\right)$; the white is magnesite $\left(\mathrm{MgCO}_{3}\right)$; and the black is carbon $(\mathrm{C})$. In order to identify the nature of the ultramarine blue, dispersions were prepared for the blue pigment and reveal fine rounded particles typical of artificial ultramarine (Fig. 10), a nineteenth century pigment.

Under SEM (Fig. 11), four layers are seen in samples: the sealing layer or varnish, the paint layer, the white preparation layer and the ground (Indications of paint layer, ground layer, and preparation layer for each crosssection are showed in Additional file 2). In some samples gold is present beneath the varnish. It is noted that in sample a and e, the particles of the blue pigment are uniform and relatively round, which suggests that they are artificial and not natural ultramarine, as confirmed by dispersions of the pigment (Fig. 10). The particle sizes 

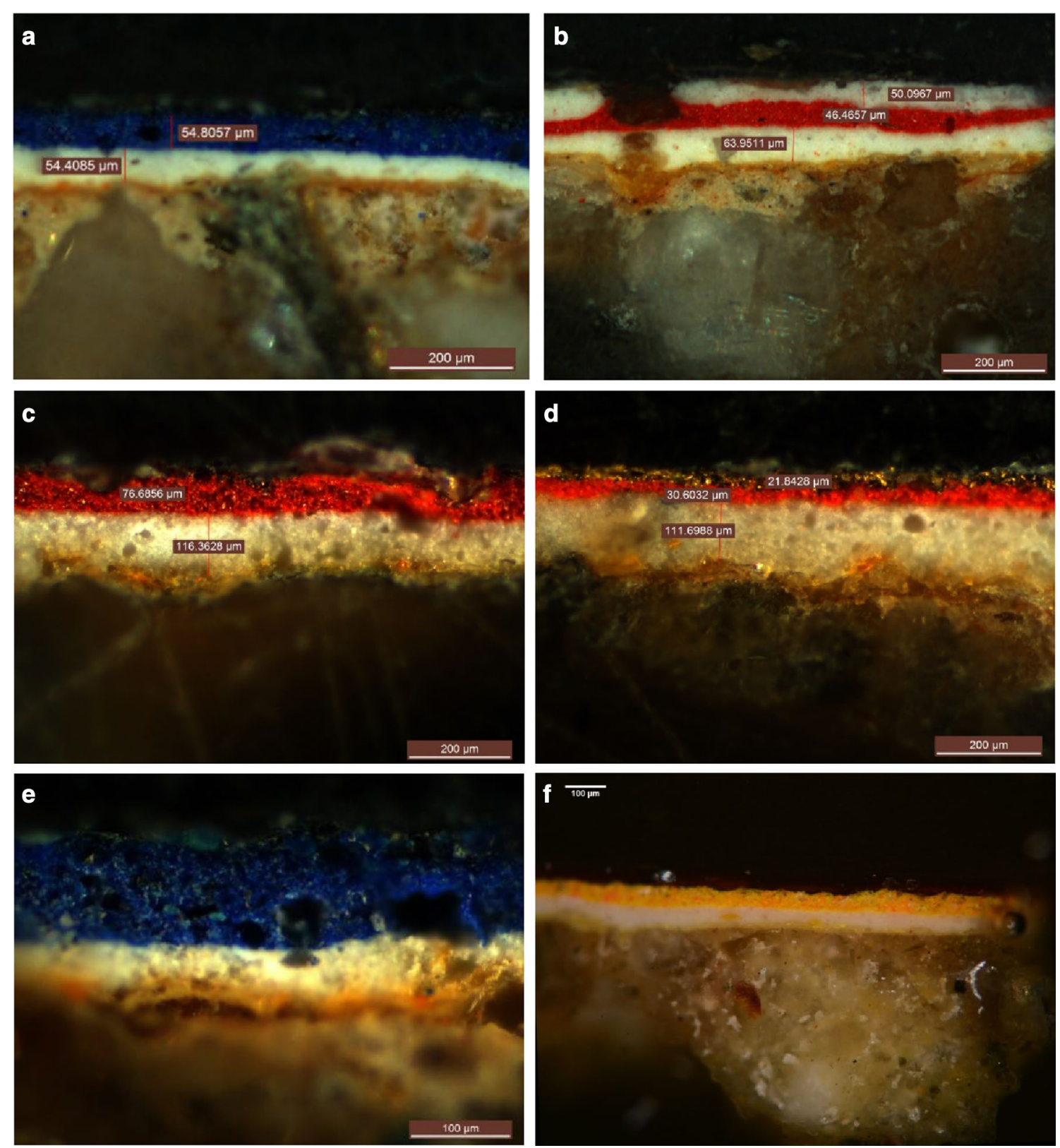

Fig. 6 Micrograph images of sample cross-sections, where different paint layers are observed. It is possible to identify clearly the presence of gold layers, repainting and ground layer build-up. (a and $\mathbf{e}$ are cross-sections of blue pigment samples; $\mathbf{b}, \mathbf{c}, \mathbf{d}$ are cross-sections of red pigment samples; $\mathbf{f}$ is cross-section of an orange pigment sample)

of the white preparation layer are small and have a uniform distribution. The EDX spectrum analysis shows that the main element is Mg. In combination with XRD and Raman, it is possible to identify the main component of the white layer as magnesite $\left(\mathrm{MgCO}_{3}\right)$. The thickness of the ground layers is different and varies in each sample.
In some samples there are two layers, while in others the preparation cannot be clearly distinguished. Clay used in the ground layers contains both quartz and feldspar particles of different sizes. 

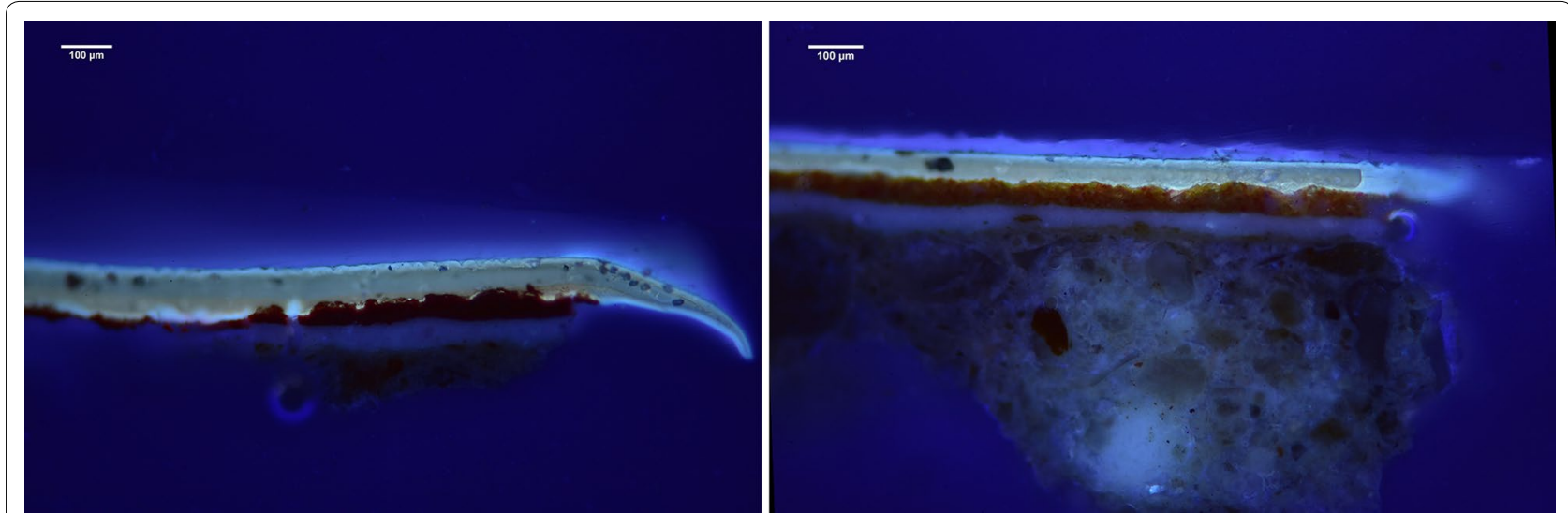

Fig. 7 Cross-sections under UV illumination. The Varnish layer is brightly fluorescent

\section{THM-Py-GC/MS analysis}

Binding media and varnish in the samples were determined by THM-Py-GC/MS. The results (see Additional file 3) showed that fatty acid (especially high content of azelaic acid), oxidation products of tung oil after heat treatment, pyrolysis products of rosin resin and maker compounds of protein, were all detected in the samples. Therefore, it is likely that the varnish contains a mixture of drying oil (maybe tung oil) and rosin resin, while the binding media is a kind of animal glue which is likely used as the binding medium for the paint and preparatory layers. According to the literature and field interviews with local painters, today Tibetan painters generally use bovine glue as binding medium, which is similar to the medium identified by THM-Py-GC/MS. Thus, the animal glue used in the wall paintings of Jokhang temple is very likely to be bovine (or yak) glue.

There is no surface protective material on the wall paintings of Tubo Period (sixth century C.E.). However, after the fifth Dalai Lama, materials were used to protect the surface of the wall paintings. The materials can increase the gloss of the surface and can prevent the loss of pigment caused by repeated touching from thousands of believers. The traditional Tibetan protective materials (such as egg white, oils, etc.) are occasionally mentioned in local treatises. However, the recipes have not been written in detail and have been lost. Since 13th Dalai Lama Period, Tibetan painters have begun to use natural protective varnishes with imported resins, which were replaced by alkyd resin varnishes during the 1970s according to accounts of local painters. Tung oil and rosin resin were detected in samples of the varnish, both of which can be dissolved in turpentine, but it is not possible to date the application of the varnish due to the use of the same materials by painters today.

\section{Implications for dating}

The pigments used on Jokhang temple wall paintings are mainly natural mineral pigments, such as ochre, red lead, cinnabar, malachite, azurite, orpiment and magnesite. These pigments are all traditional pigments which are often used by Tibetan artists [21-24]. It is noted that the same mineral can show a variety of colors by different degree of grinding or different processing methods, and that malachite and azurite are often found together, as observed in cross-sections.

In addition to traditional mineral pigments, synthetic pigments, such as Paris green and artificial ultramarine are also detected. These two synthetic pigments were produced in Europe in early nineteenth century. Subsequently, they began to enter China and were identified on many paintings, architectural painting and temple murals of the late Qing Dynasty. For example, Paris green has been found in the pigments of a late Qing Dynasty Taoist portraits [39], the architectural painting of Zhendu gate in the Imperial Palace [40] and the Qing Dynasty wall painting in the Potala Palace and Drepung Monastery $[41,42]$. The use of artificial ultramarine is more extensive than Paris green. In China, many paintings from the late Qing Dynasty were executed in artificial ultramarine. For example, most murals and painted sculptures of Qing Dynasty in Dun Huang grotto used artificial ultramarine [43]. Because Paris green and artificial ultramarine were also found in the samples of Jokhang temple, it is concluded that the wall paintings in the outside galley of Jokhang temple have been repaired and repainted in late Qing Dynasty, thus during the mid-nineteenth century or later.

\section{Conclusion}

Combining site investigations with sampling analysis, the materials and production process of Jokhang temple wall paintings have been studied. The results show that most 


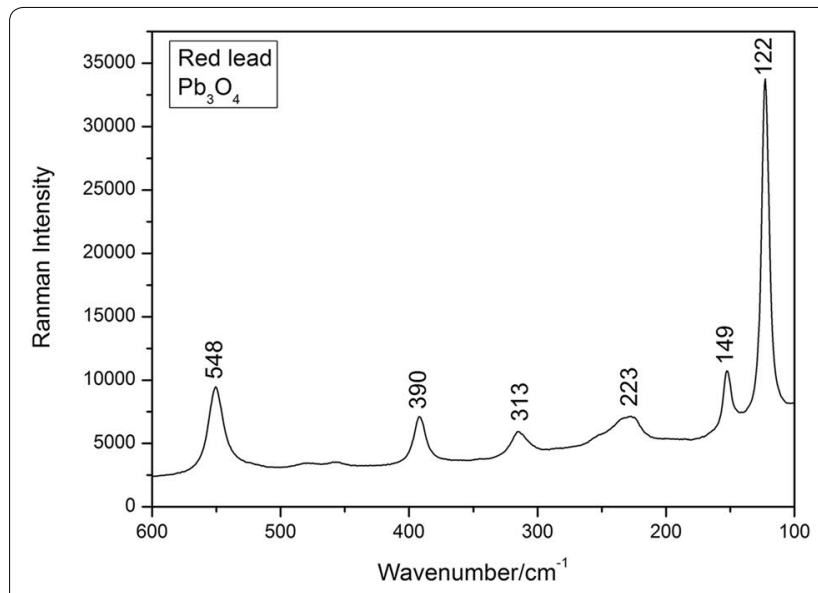

a

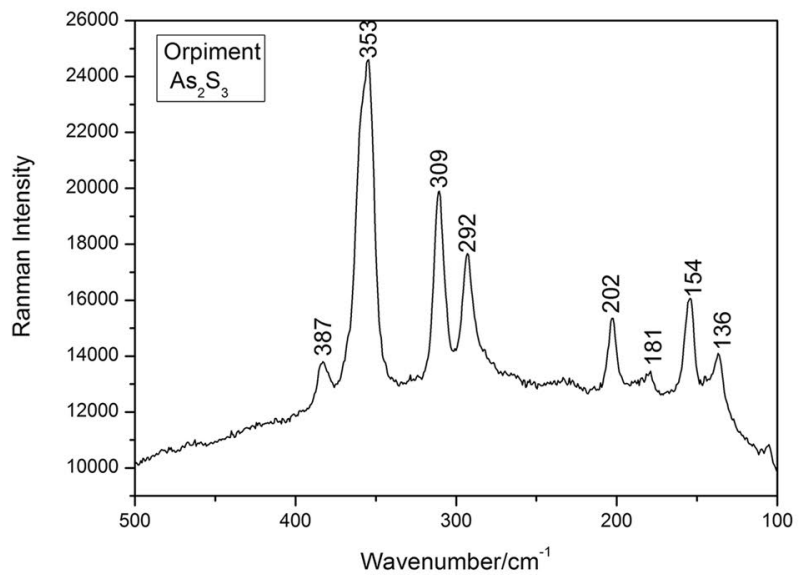

C

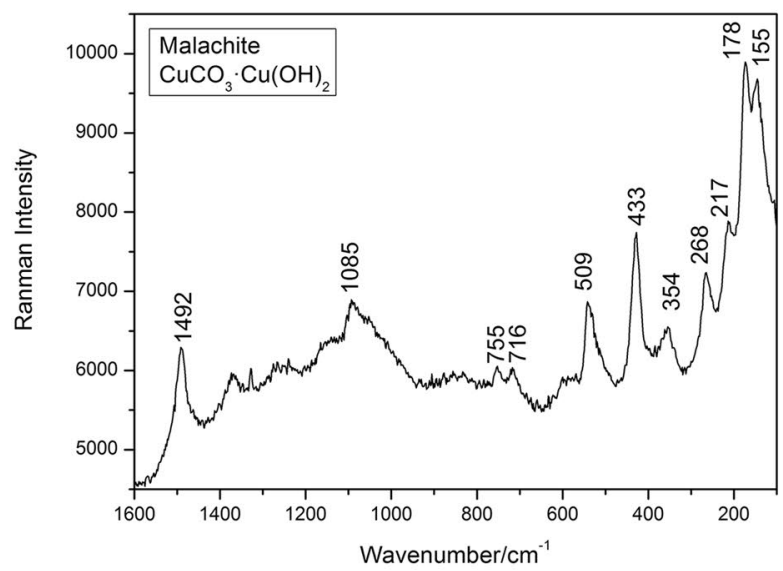

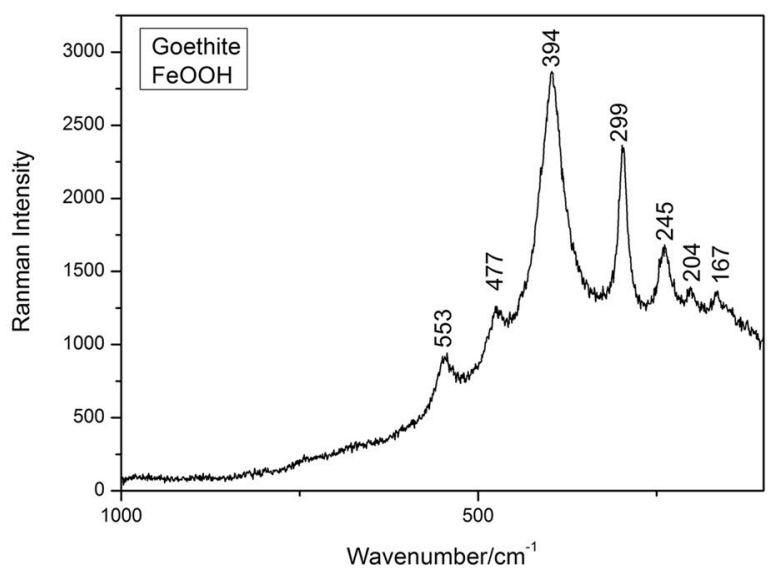

b

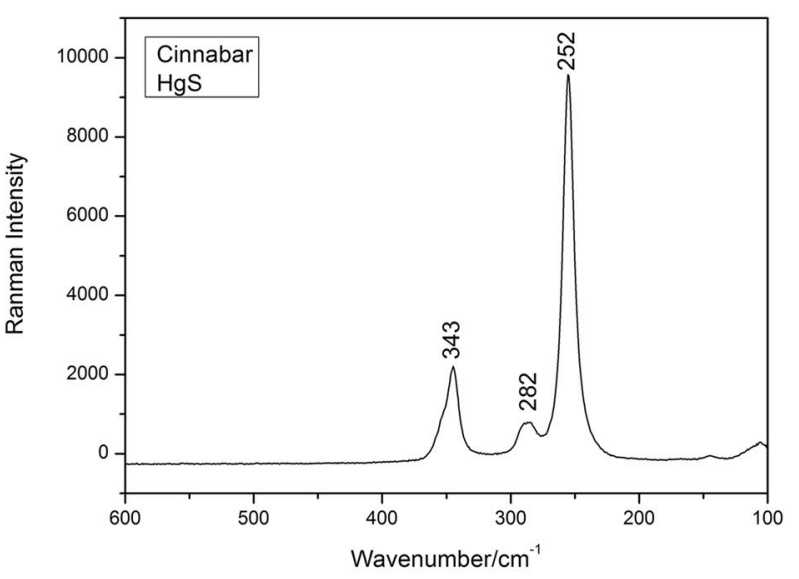

d

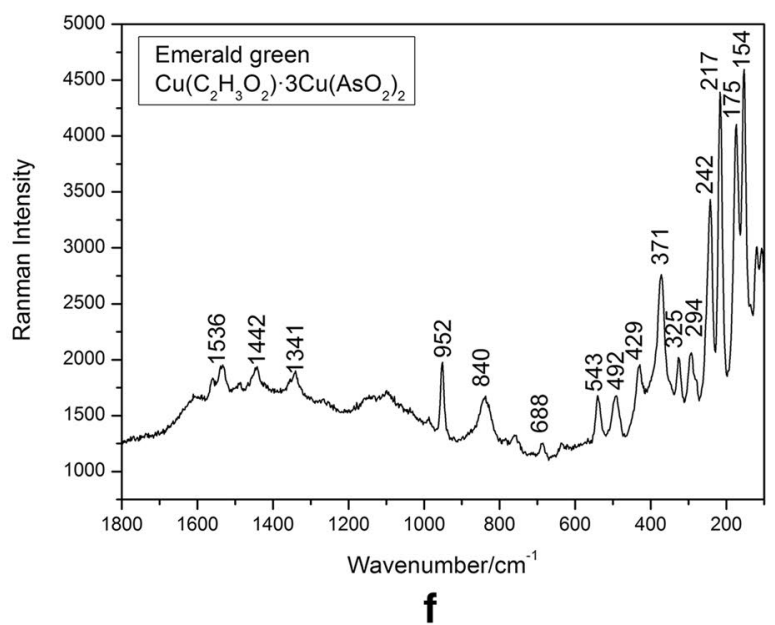

Fig. 8 Representative Raman spectra of samples from the Jokhang temple wall paintings, with key bands labelled for the identification of pigments. For analysis laser wavelengths used are 532 and $785 \mathrm{~nm}$. a red/orange i particles, b orange particles, c yellow particles, $\mathbf{d}$ red particles, e, $\mathbf{f}$ green particles 


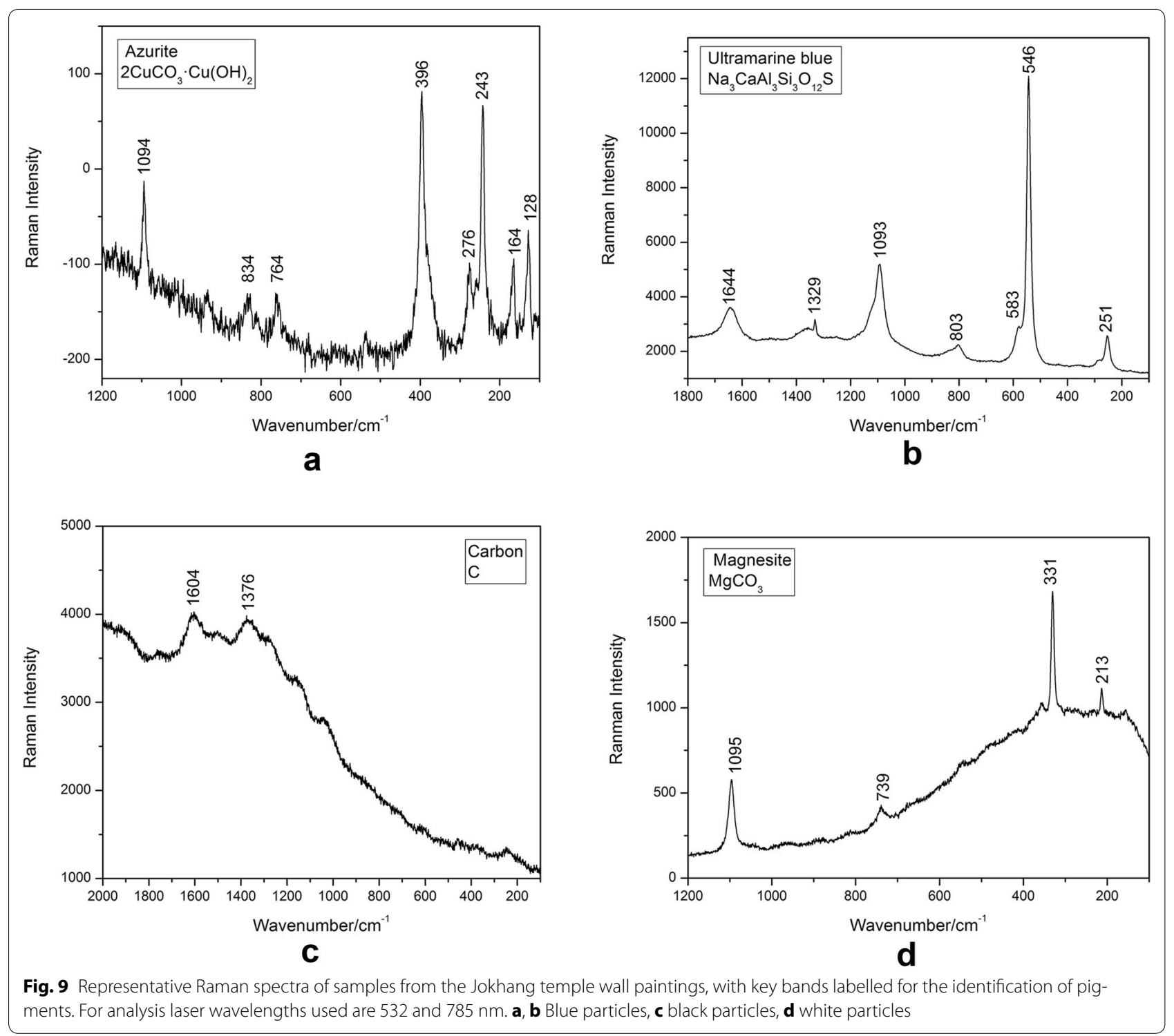

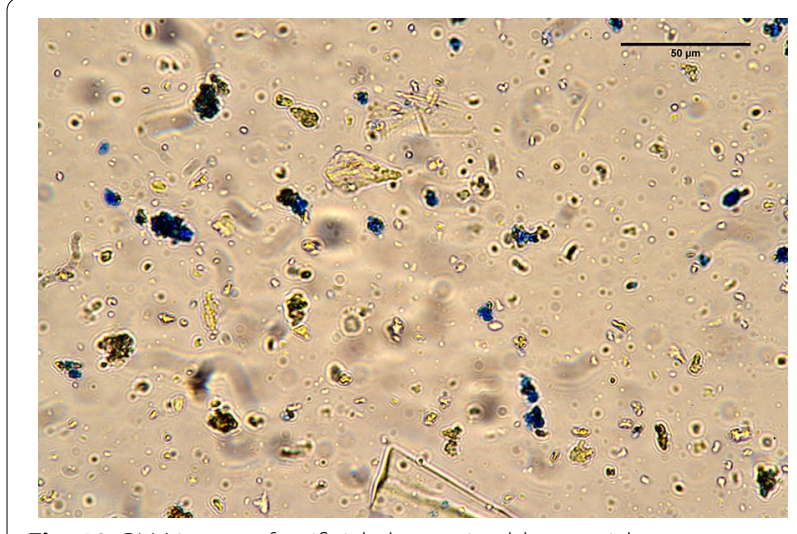

Fig. 10 PLM image of artificial ultramarine blue particles pigments used in the wall paintings are natural mineral pigments, such as cinnabar, azurite, malachite green, dark blue, red lead and orpiment. At the same time, some synthetic pigments, such as emerald green and artificial ultramarine are also found, indicating that the wall paintings have been repaired or repainted more recently (maybe in mid or late nineteenth century). In addition to natural mineral and artificial pigments, gold powder and gold foil were also used widely in the wall paintings. The wall paintings are made with Tibetan traditional craft and contain multiple ground layers, white preparation layer, paint layer and a thick surface varnish which contained drying oil (maybe tung oil) and pine resin. The binding media used in the paint is a kind of animal glue which is likely to be bovine/yak glue according to the tradition 

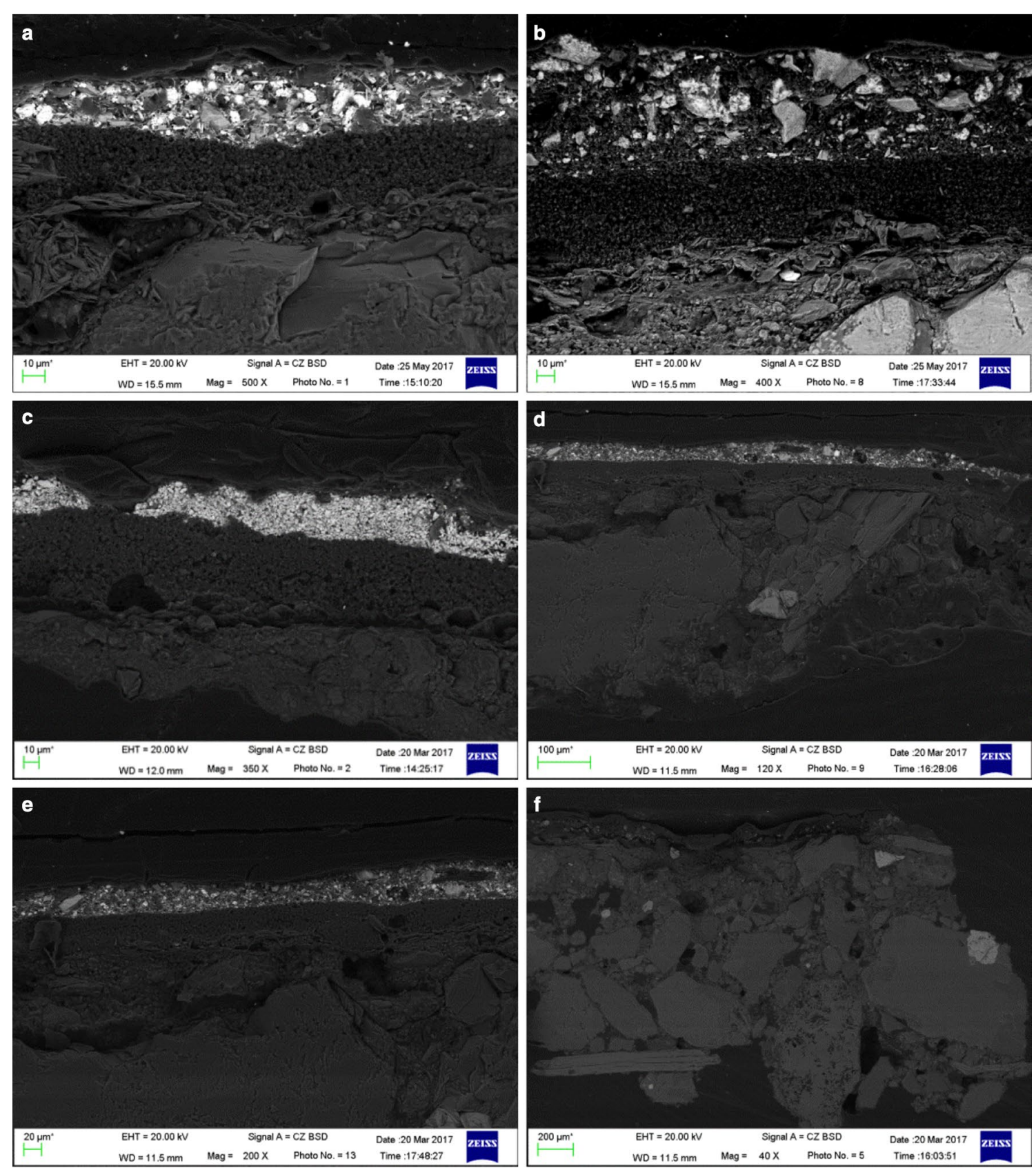

Fig. 11 Representative images of sample cross-sections acquired with SEM(a and $\mathbf{e}$ are images of blue pigment sample; $\mathbf{b}$ is image of green pigment sample; $\mathbf{c}$ is image of red pigment sample; $\mathbf{d}$ is image of orange pigment sample; $\mathbf{f}$ is image of the ground layer of one sample)

of Tibet. While the conservation of the wall paintings requires careful monitoring of the condition of the polychromy surface, the main causes of damage are human beings who touch the surfaces, and the failure of the building fabric, which requires routine inspection and regular maintenance. Efforts should thus be focused on preventive measures to ensure the long-term conservation of these important paintings.

\section{Additional files}

Additional file 1. Location of Raman Spectroscopy Analysis of Crosssections (Carbon and Azurite were detected on some pigment particles, so we didn't save their location).

Additional file 2. Annotated SEM Images with indications of paint layer, ground layer, and preparation layer for each cross-section

Additional file 3. Results of Organic Analysis. 


\section{Authors' contributions}

YS contributed to sample and data analysis, interpretation and manuscript writing. AN was involved in the sample analysis and manuscript revision. FG, $X Z$, JG and QL were involved in the initial concept of the experiments and collected the data used in this paper. SW supplied the results of Py-GC/MS. All authors read and approved the final manuscript.

\section{Author details}

${ }^{1}$ Chinese Academy of Cultural Heritage, No. 2 Gaoyuan Street, North Fourth Ring Road, Chaoyang District, Beijing, China. ${ }^{2}$ Istituto di Fotonica e Nanotecnologie - Consiglio Nazionale delle Ricerche (IFN-CNR), Piazza Leonardo da Vinci 32, 20133 Milan, Italy. ${ }^{3}$ University of Science and Technology Beijing, 30 Xueyuan Road, Haidian District, Beijing, China.

\section{Acknowledgements}

The authors would like to thank the Jokhang temple Management Committee for supplying the wall painting samples and historical background. The authors also acknowledge Dr. Qinglin Ma for his good advice in paper writing, and Dr. Bo Xiao for the technical help of THM-Py-GC/MS

\section{Competing interests}

The authors declare that they have no competing interests.

\section{Availability of data and materials}

Not applicable.

\section{Ethics approval and consent to participate}

The paper presented is the work made by our independent research. All data cited in the paper were from publicly available datasets and published literatures. In addition to the content of particular references, this paper does not contain any work that has been published or written by any other individual or group. Individuals, who have made important contributions to the study of this paper, have been clearly demonstrated in the acknowledgements.

\section{Funding}

This research was supported by "Basic research funds of Chinese Academy of Cultural Heritage". Award Number: 2016-JBKY-13. Grant Recipient: Yan Song.

\section{Publisher's Note}

Springer Nature remains neutral with regard to jurisdictional claims in published maps and institutional affiliations.

Received: 25 September 2017 Accepted: 8 March 2018

Published online: 23 March 2018

\section{References}

1. Fu CL. History of Lhasa. Beijing: China Social Sciences Press; 1994 (in Chinese).

2. Cultural Relics management committee of Tibet autonomous region, Lhasa cultural relics, Xianyang: Xianyang printing plant. 1985 (in Chinese).

3. Sonam. The biography of the king of Tibet. Beijing: The Ethnic Publishing House; 2000 (in Chinese)

4. Ngawang Lobsang Gyatso. The fifth Dalai Lama biography. Beijing: China Tibetology Press; 2006 (in Chinese)

5. Lobsang TuDan. The Eighth Dalai Lama biography. Beijing: China Tibetology Press; 2006 (in Chinese)

6. Dai ZM. Wishful rattan: Sakyamuni Biography. Chengdu: SiChuan Ethnic Publishing House; 1998 (in Chinese).

7. Tinley. Tibetan customs. Lhasa: The Tibet people's Publishing House; 2007 (in Chinese)

8. Su B. Archaeology of Tibetan buddhist monastery. Beijing: Cultural Relics Press; 1996 (in Chinese).

9. Yang CB. Jokhang temple resplendent on the roof of the world. China's Tibet. 1994;6:11-2 (in Chinese)

10. Wang Y, Chen QY. Tibetan history and culture dictionary. Lhasa: The Tibet People's Publishing House; 1998 (in Chinese).
11. Sonan. The biography of Tibetan king's servants. Lhasa: Tibet People's Publishing House; 1985 (in Chinese).

12. Lhasa literature and history group. History of the Jokhang temple. Tibet Res. 1981;00:36-50 (in Chinese).

13. Jackson D. History of Tibetan painting. Lhasa: Tibet people's Publishing House; 2001 (in Chinese).

14. Zhang YS. History of Tibetan art. Beijing: Central University for Nationalities Press; 2006 (in Chinese).

15. Gozengdan. Tibetan unique art. Lanzhou: Gansu National Publishing House; 2001 (in Chinese).

16. Ye XS. Mural painting of Tibet Jokhang temple. Collections. 2010;1:116-9 (in Chinese)

17. Tucci G. Tibet, land of snows. London: Oxford \& IBH Publishing Co.; 1967.

18. Singer JC. Painting in central Tibet, ca. 9 50-1400. Artibus Asiae. 1994;54(1/2):87-136.

19. Singh AK. Trans-Himalayan wall paintings: 10th to 13th century AD. Delhi: Agam Kala Prakashan; 1985.

20. Xiang JT. Study of the murals on the Jokhang temple pilgrimage-corridor walls, Doctoral Dissertation of Minzu University of China. 2007. (in Chinese).

21. Wang $L L, L i Z M$, Zhang $X T$, et al. Studies on wall painting techniques at Jokhang temple, Lhasa, Tibet, China. Sci Conserv Archaeol. 2014;26(4):8492 (in Chinese).

22. Li ZM, Wang LL, Zhang XT, et al. Study on field analysis of mural pigments by portable $\mathrm{x}$-ray fluorescence: to the Jokhang temple murals as an example. China Cult Heritage Sci Res. 2013;4:64-7 (in Chinese).

23. Wang Y, Zhang XT, Wu N. Raman spectroscopic analysis of wall painting pigments at Jokhang temple, Lhasa, Tibet, China. J Light Scatt. 2017;29(1):39-43 (in Chinese)

24. Wang WF, Ma ZF, Yu ZR. An analysis on the materials of murals in Potala Palace, Norbuglinkha and Sakya Monastery, Tibetan. Dunhuang Res. 2002;6:78-84 (in Chinese).

25. Yu ZR, Zhao LY, Li YF. Analysis of the paint of the Horseshoe temple, TianTiShan and BingLing temple. Dunhuang Res. 2005;4:67-70 (in Chinese).

26. Chen GL. Analysis of pigments and clay of the polychrome statue and wall paintings in the No. 9 Tiantishan Grotto. Sci Conserv Archaeol. 2010;22(4):91-6 (in Chinese)

27. Wang $X Q$, Wang $C S$, Yang JL. Analysis of wall painting pigments in Fenghui tomb using HREM and Raman spectroscopy. J Instrum Anal. 2004:23(3): 1-4 (in Chinese).

28. Zhang SX, Zhu J, Wang CS. The wall-painting pigments in A-Er-Zhai of Inner-Mongolia were analyzed by Raman microscopy. Relics South. 2009;1:109-12 (in Chinese)

29. Wang JY, Wang M, Liu L. Raman spectroscopy in archaeology. Chin J Light Scatt. 2006;18(2):130 (in Chinese).

30. Xia Y, Guo H, Wang JH. A study of the mural pigments of A-er-zhai Grottos, Inner Mongolia. Sci Conserv Archaeol. 2007;19(2):41-6 (in Chinese).

31. Ruiz-Moreno S, Pérez-Pueyo R, Gabaldón A, et al. Raman laser fibre optic strategy for non-destructive pigment analysis. Identification of a new yellow pigment ( $\mathrm{Pb}, \mathrm{Sn}, \mathrm{Sb})$ from the Italian XVII century painting. J Cult Heritage. 2003;4:309-13.

32. Breitman M, Ruiz-Moreno S, Pérez-Pueyo R. Study of Raman spectra of pigment mixtures. J Cult Heritage. 2003:4:314-6.

33. Coma L, Breitman M, Ruiz-Morenno S. Soft and hard modeling methods for deconvolution of mixtures of Raman spectra for pigment analysis: a qualitative and quantitative approach. J Cult Heritage. 2000;1:273-6.

34. Yu XD. History of Tibetan Buddhist Painting. Nanjing: Jiangsu Arts Publishing House; 2006 (in Chinese)

35. Kelsang Yeshi. Tibetan art history. Chengdu: Sichuan National Publishing House; 2005 (in Chinese).

36. Dambar. A brief history of Tibetan art. Lhasa: The Tibet people's Publishing House. 2003. (in Chinese).

37. Bell IM, Clark RJH, Gibbs PJ. Raman spectroscopic library of natural and synthetic pigments (pre- $\approx 1850$ AD). Spectrochim Acta Part A Mol Biomol Spectrosc. 1997;53(12):2159-79.

38. Rutt HN, Nicola JH. Raman spectra of carbonates of calcite structure. $J$ Phys C Solid State Phys. 1974;7:4522-8.

39. He QJ, Li T, Shi JL. Non-destructive in situ characterization of pigments on a portrait of Chinese Taoism figure. Sci Conserv Archaeol. 2010;03(22):61-8 (in Chinese). 
40. Cheng XL, Xia Y, Ma YR, et al. Three fabricated pigments (Han Purple, indigo and emerald green) in ancient Chinese artifacts studied by Raman microscopy, energy-dispersive X-ray spectrometry and polarized light microscopy. J Raman Spectr. 2007:38:1274-9.

41. Xia Y. Exploring Chinese historical pigments by optical microscopy. Relics Museol. 2009;6:342-6 (in Chinese).
42. Cheng XL, Yang Q. Micro-Raman spectroscopy study of three green pigments containing copper and arsenic. Sci Conserv Archaeol. 2015;27(3):84-9 (in Chinese).

43. Wang JY. Study of artificial ultramarine in Dunhuang grottoes. Dunhuang Res. 2010;1:76-81 (in Chinese).

\section{Submit your manuscript to a SpringerOpen ${ }^{\odot}$ journal and benefit from:}

- Convenient online submission

- Rigorous peer review

- Open access: articles freely available online

- High visibility within the field

- Retaining the copyright to your article

Submit your next manuscript at $\boldsymbol{\nabla}$ springeropen.com 